Article

\title{
Giant Vertical Magnetization Shift Caused by Field-Induced Ferromagnetic Spin Reconfiguration in $\mathrm{Ni}_{50} \mathrm{Mn}_{36} \mathrm{Ga}_{14}$ Alloy
}

\author{
Fanghua Tian, Yin Zhang, Chao Zhou, Qizhong Zhao, Zhonghai Yu, Adil Murtaza, Wenliang Zuo, \\ Sen Yang * and Xiaoping Song \\ MOE Key Laboratory for Nonequilibrium Synthesis and Modulation of Condensed Matter, School of Physics, \\ Xi'an Jiaotong University, Xi'an 710049, China; tfh2017@xjtu.edu.cn (F.T.); yzhang18@xjtu.edu.cn (Y.Z.); \\ chao.zhou@xjtu.edu.cn (C.Z.); zhaoqizhong@stu.xjtu.edu.cn (Q.Z.); yuzhh1123@stu.xjtu.edu.cn (Z.Y.); \\ adilmurtaza91@mail.xjtu.edu.cn (A.M.); zuowenliang@xjtu.edu.cn (W.Z.); xpsong@xjtu.edu.cn (X.S.) \\ * Correspondence: yang.sen@xjtu.edu.cn
}

Received: 18 September 2020; Accepted: 19 October 2020; Published: 22 October 2020

\begin{abstract}
Vertical magnetization shift (VMS) is a special type of exchange bias effect that may lead to a revolution in future ultrahigh-density magnetic recording technology. However, there are very few reports focusing on the performance of VMS due to the unclear mechanism. In this paper, a giant vertical magnetization shift $\left(\mathrm{M}_{\mathrm{E}}\right)$ of $6.34 \mathrm{emu} / \mathrm{g}$ is reported in the $\mathrm{Ni}_{50} \mathrm{Mn}_{36} \mathrm{Ga}_{14}$ alloy. The VMS can be attributed to small ferromagnetic ordered regions formed by spin reconfiguration after field cooling, which are embedded in an antiferromagnetic matrix. The strong cooling-field dependence, temperature dependence, and training effect all corroborate the presence of spin reconfiguration and its role in the VMS. This work can enrich VMS research and increase its potential in practical applications as well.
\end{abstract}

Keywords: Heusler alloy; spin glass; vertical magnetization shift; spin reconfiguration

\section{Introduction}

Since the discovery of the exchange bias effect, it has been utilized to fabricate hard disk drives, spin valves, magnetic tunnel junctions, and other "spin electronic" devices [1-4]. There are two main types of exchange bias effect research, the horizontal exchange bias effect (EB) and the vertical magnetization shift (VMS). EB is the offset of the hysteresis loop along the field axis, which is observed and studied in many materials [5-12]; VMS is the offset of the hysteresis loop along the magnetization axis, which is only found in a small number of systems [13-18]. $\mathrm{M}_{\mathrm{E}}$ denotes the shift of the center of gravity of the hysteresis loop along the magnetization axis. It is a measure of the average value of magnetizations at the positive and negative measuring fields $\left(\mathrm{M}_{\max +}\right.$ and $\mathrm{M}_{\max -}$, respectively), $\mathrm{M}_{\mathrm{E}}=\left(\mathrm{M}_{\max +}+\mathrm{M}_{\max -}\right) / 2$ [13-15]. For example, Tian et al. obtained an $\mathrm{M}_{\mathrm{E}}=0.15 \mathrm{emu} / \mathrm{g}$ in $\mathrm{NiFe}_{2} \mathrm{O}_{4}$ nanoparticles. The observed VMS is explained in terms of the exchange interaction between the ferrimagnetic phase and the spin glass-like (SG) phase at the interface [13]. Zheng et al. reported an $\mathrm{M}_{\mathrm{E}}=45 \mathrm{emu} / \mathrm{cm}^{3}$ in $\mathrm{SrRuO}_{3} / \mathrm{SrTiO}_{3}$ heterostructures due to the lattice distortion caused by the oxygen deficiency, which modifies the strong hybridization of $p-d$ orbitals and perpendicular uniaxial magnetic anisotropy [15]. So far, the reported $\mathrm{M}_{\mathrm{E}}$ is relatively small, and a comprehensive understanding of the VMS effect is still disputed, restricting the practical applications of VMS.

$\mathrm{Ni}-\mathrm{Mn}-\mathrm{Z}(\mathrm{Z}=\mathrm{Ga}, \mathrm{Sn}, \mathrm{In}, \mathrm{Sb})$ Heusler alloys have attracted much attention and have been extensively studied in the past decade [19-21], because off-stoichiometric Ni-Mn-Z Heusler alloys contain two mixed phases: (i) the conventional interaction of $\mathrm{Mn}$ atoms produces ferromagnetism; (ii) an additional interaction of the Mn atoms produces antiferromagnetism. In some regions, the 
antiferromagnetic (AFM) interaction becomes stronger than the ferromagnetic (FM) interaction, thereby producing AFM regions, while in other regions, an SG state will occur due to the interaction of the two types of magnetic states at low temperatures [22,23]. Furthermore, over a very large composition range, a reversible martensitic transformation may occur in the alloys, producing complex magnetic properties at low temperatures. The interplay between magnetic and structural degrees of freedom produces many unique functional properties, including a large magnetocaloric effect, giant magnetoresistance, large magnetic-field-induced strains, and large EB [24-27]. It can be known from the previous literature that in the $\mathrm{Ni}_{50} \mathrm{Mn}_{25+X} \mathrm{Ga}_{25-\mathrm{X}}(0 \leq \mathrm{x} \leq 25)$ alloy, when $\mathrm{x} \leq 15$, the alloy enters the spin glass state of the FM and AFM interaction at low temperatures [28,29]. This interaction can lead to the EB effect. For example, Han et al. observed the EB effect both after the field cooling (FC) and zero field cooling (ZFC) process in off-stoichiometric $\mathrm{Ni}_{50} \mathrm{Mn}_{35} \mathrm{Ga}_{15}$ alloy [29].

In this work, the VMS is studied in the $\mathrm{Ni}_{50} \mathrm{Mn}_{36} \mathrm{Ga}_{14}$ Heusler alloy. Besides, a systematic investigation of the effects of the temperature and cooling field on $\mathrm{M}_{\mathrm{E}}$ is analyzed, giving a new way to further understanding and improvement of tunable spintronic devices. This discovery can also enrich the VMS research and increase its potential in practical applications.

\section{Material and Methods}

In this study, bulk polycrystalline $\mathrm{Ni}_{50} \mathrm{Mn}_{36} \mathrm{Ga}_{14}$ alloy was prepared by arc melting and cast into a copper mold under argon atmosphere. For homogenization, the prepared alloy was sealed in a silica tube furnace and annealed at $1173 \mathrm{~K}$ for $24 \mathrm{~h}$. The annealing temperature is generally selected as a temperature slightly below the melting temperature [28]. It is known from the literature that the melting temperature of NiMnGa alloy is about $1300 \mathrm{~K}$ [30], so the annealing temperature used in this article was $1173 \mathrm{~K}$. X-ray diffraction (XRD) measurements were performed using a Bruker D8 X-ray diffractometer (Bruker, D8 ADVANCE, Miroslava Minkova, Germany) with Cu K $\alpha 1$ radiation. The phase transformation temperature was determined by differential scanning calorimetry (DSC, TA Instruments-Waters, Q2000, New Castle, DE, USA) with a heating/cooling rate of $10 \mathrm{~K} / \mathrm{min}$. Compositional analysis was performed by means of energy dispersive spectroscopy (EDS, JEOL JSM-7000F, Tokyo, Japan) of the samples. The magnetic properties including, the magnetic hysteresis (M-H) loops, magnetization-temperature (M-T) curves, and AC susceptibility were measured using a superconducting quantum interference device (SQUID) magnetometer (Quantum Design, MPMS-XL-5, San Diego, CA, USA).

\section{Results}

The XRD pattern of the bulk $\mathrm{Ni}_{50} \mathrm{Mn}_{36} \mathrm{Ga}_{14}$ alloy at room temperature is shown in Figure 1a. The observed pattern is consistent with a single tetragonal $\mathrm{L} 1_{0}$ structure (martensitic phase) [31,32]. The calculated results are based on the tetragonal structure with space group $P 4 / \mathrm{mmm}$, and the small values of the reliability factors $\left(R_{P}\right.$ : profile factor, $R_{W P}$ : weighted profile factor, $\chi^{2}$ : goodness of fit) of the Rietveld refinements suggest the good agreement between the experimental and calculated diffraction patterns of the sample. The alloy has the following lattice parameters at room temperature: $\mathrm{a}=\mathrm{b}=7.6077 \AA$ and $\mathrm{c}=6.7976 \AA$. The temperature hysteresis of heat flow transition peaks obtained through the DSC measurements is shown in Figure 1b. The start and the end of the transformation temperatures have been determined by the intersection of a baseline and the tangents to each peak. Its characteristic martensitic phase transition temperatures, i.e., the austenite start and finish temperatures $\left(A_{s}\right.$ and $\left.A_{f}\right)$ and the martensite start and finish temperatures $\left(M_{s}\right.$ and $\left.M_{f}\right)$, were determined to be 591 $\pm 0.2,601 \pm 0.2,589 \pm 0.2$, and $580 \pm 0.2 \mathrm{~K}$, respectively. The sample undergoes the endothermic process with a phase transformation enthalpy of $1.85 \mathrm{~J} / \mathrm{g}$ upon heating, and upon cooling, it undergoes the exothermic process with an enthalpy of $1.83 \mathrm{~J} / \mathrm{g}$. The enthalpy difference between them is only about $0.02 \mathrm{~J} / \mathrm{g}$, showing good reversibility of the phase transformation. The first-order nature of the phase transition was also confirmed from the observed temperature hysteresis (12 K) of heat flow transition peaks. In addition, Figure S1 plots the DSC measurement results of the $\mathrm{Ni}_{50} \mathrm{Mn}_{36} \mathrm{Ga}_{14}$ 
alloy for 15 consecutive heating and cooling thermal cycles. It can be clearly seen that after 15 cycles, the martensitic transformation peak has only moved about $1.5 \mathrm{~K}$ compared to the first cycle, which indicates that the phase transition of the $\mathrm{Ni}_{50} \mathrm{Mn}_{36} \mathrm{Ga}_{14}$ alloy has good reproducibility. From the above $\mathrm{XRD}$ and DSC results, it can be concluded that the alloy is a martensitic phase with $\mathrm{L} 1_{0}$ structure at room temperature.

(a)

(b)
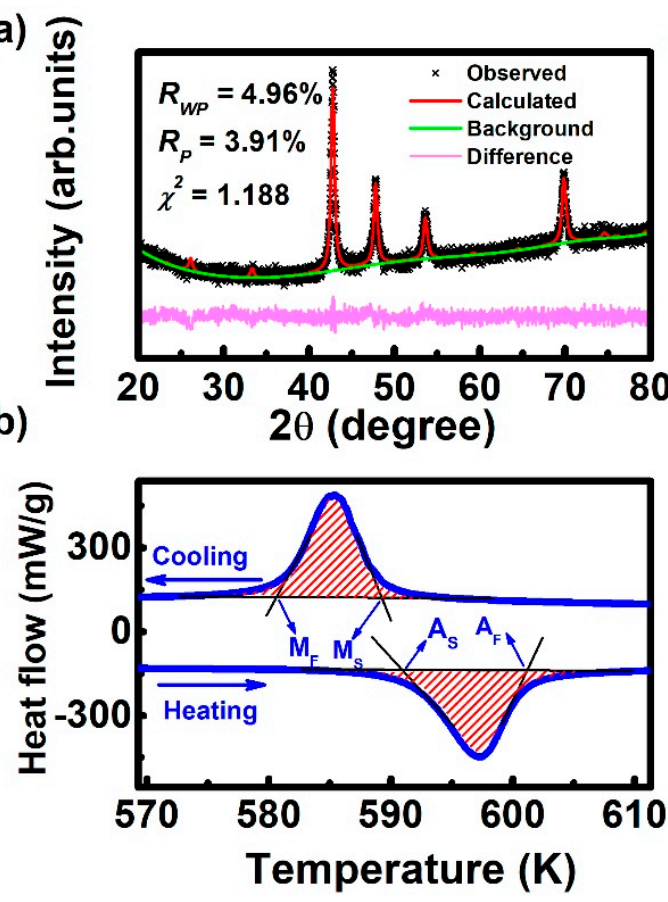

(c)

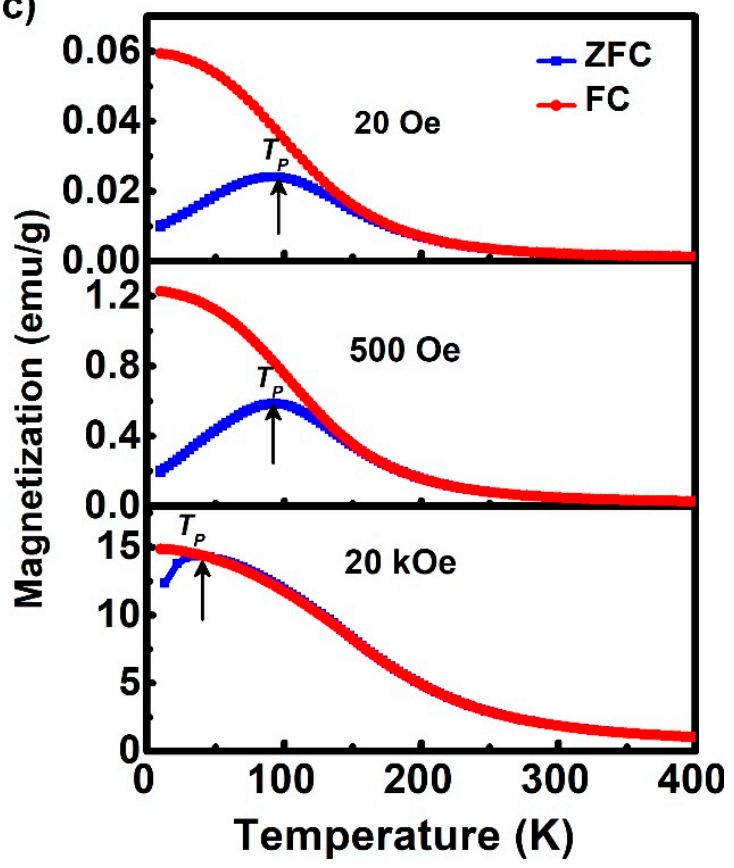

Figure 1. (a) XRD pattern of the $\mathrm{Ni}_{50} \mathrm{Mn}_{36} \mathrm{Ga}_{14}$ alloy at room temperature. (b) Martensitic transformation behavior of the alloy measured by DSC using a cooling/heating rate of $10 \mathrm{~K} / \mathrm{min}$. (c) Temperature dependence of the magnetization curves for an applied magnetic field of $20 \mathrm{Oe}, 500 \mathrm{Oe}$, and $20 \mathrm{kOe}$ for zero field cooling (ZFC) and FC, respectively.

Figure 1c presents the temperature dependence of magnetization measured under ZFC and FC of the $\mathrm{Ni}_{50} \mathrm{Mn}_{36} \mathrm{Ga}_{14}$ alloy under different applied magnetic fields, and the rate is $3 \mathrm{~K} / \mathrm{min}$. In the case of the ZFC curve, the magnetization first increases and then decreases with decreasing temperature and reaches a maximum at $\sim 110 \mathrm{~K}$. On the other hand, the observed FC curve shows an FM-like behavior. The large splitting between the ZFC and FC curves at low temperatures indicates an inhomogeneous magnetic state (i.e., an SG or AFM state with FM regions) in this regime $[5,8,33]$. The temperature dependence of magnetization was also measured under an applied magnetic field of 500 Oe and 20 kOe (shown in the middle and bottom panel of Figure 1c, respectively). In this case, the bifurcation of the FC and ZFC curves appears after the temperature decreased to $100 \mathrm{~K}$ and $35 \mathrm{~K}$, respectively, indicating that after a high field cooling, SG behaves like FM. Such a feature is also typical for glassy magnetic states in the case of a martensitic phase transformation [3].

At the same time, the element ratio of the annealed alloy was analyzed by EDS. The result is given in Figure S2, which illustrates analytical spectra and the corresponding alloy composition. It is seen that the atomic percentage (at \%) of $\mathrm{Ni}, \mathrm{Mn}$, and $\mathrm{Ga}$ is $51.2 \pm 1,34.5 \pm 1$, and $14.3 \pm 1$, respectively. It deviates from the nominal composition $\left(\mathrm{Ni}_{50} \mathrm{Mn}_{36} \mathrm{Ga}_{14}\right)$ at an acceptable level.

For comparison, the XRD, DSC, and MT of the as-cast were also studied, as shown in Figure S2. Figure S2a shows DSC scans for as-cast and annealed $\mathrm{Ni}_{50} \mathrm{Mn}_{36} \mathrm{Ga}_{14}$. In both the as-cast and annealed alloys, a couple of peaks indicate a martensitic transformation during the cooling and heating, but the peak is much broader in the as-cast alloy. Thus, annealing helps to achieve compositional homogeneity. This is because, during annealing, the elements in the alloy can diffuse more sufficiently 
to reduce the inhomogeneity of the chemical composition (segregation). X-ray diffraction patterns of both alloys recorded at room temperature are shown in Figure S2b. The structure of both alloys is almost identical, except for slight differences in the peak intensities and angles. The magnetic moment measurements revealed that upon annealing, a significant increase of magnetization occurs (Figure S2c). In the following, the annealed samples are used for all measurements.

An obvious feature of SG is that it has a memory effect, which can be tested through the stop-and-wait protocol [34]. In the SG state, when the temperature is lower than $T_{P}$, the size of the glass will grow with the waiting time even under the ZFC process, showing a good memory effect. Figure 2 shows the stop-and-wait protocol test of the $\mathrm{Ni}_{50} \mathrm{Mn}_{36} \mathrm{Ga}_{14}$ alloy. First, cool the sample from $400 \mathrm{~K}$ to 2 $\mathrm{K}$ without an external field, and then, record the change of the magnetization curve with temperature (Curve 1, as the reference curve) while under a 200 Oe external field during heating. Then, add the stop-and-wait procedure: first cool the sample from $400 \mathrm{~K}$ to the intermediate stop temperature $\mathrm{T}_{\mathrm{W}}=$ $50 \mathrm{~K}\left(\mathrm{~T}_{\mathrm{W}}<\mathrm{T}_{\mathrm{P}}\right)$ under the ZFC process, where the sample waits for $\mathrm{t}=10^{4} \mathrm{~s}$, and then, further cool to 2 $\mathrm{K}$; the data were recorded during the heating process with an external 200 Oe magnetic field as Curve 1 (Curve 2). As shown in Figure 2, the magnetization of the two magnetization curves basically overlaps in all other temperature regions, except for the inconsistency near $50 \mathrm{~K}$. The difference between Curves 2 and 1 is shown in the inset of Figure 2. It can be clearly observed that the alloy memory effect is around $50 \mathrm{~K}$. This memory effect confirms that martensite exhibits the SG behavior at a temperature lower than $\mathrm{T}_{\mathrm{P}}$. Moreover, the temperature dependence of the electrical resistivity is presented in Figure S4. The resistivity shows an insulator behavior at higher temperatures, but around $\mathrm{T}_{\mathrm{P}}$, an insulator-metal transition occurs, which may be ascribed to the effect of spin-disorder scattering of frozen spins in the magnetic inhomogeneous SG state [35].

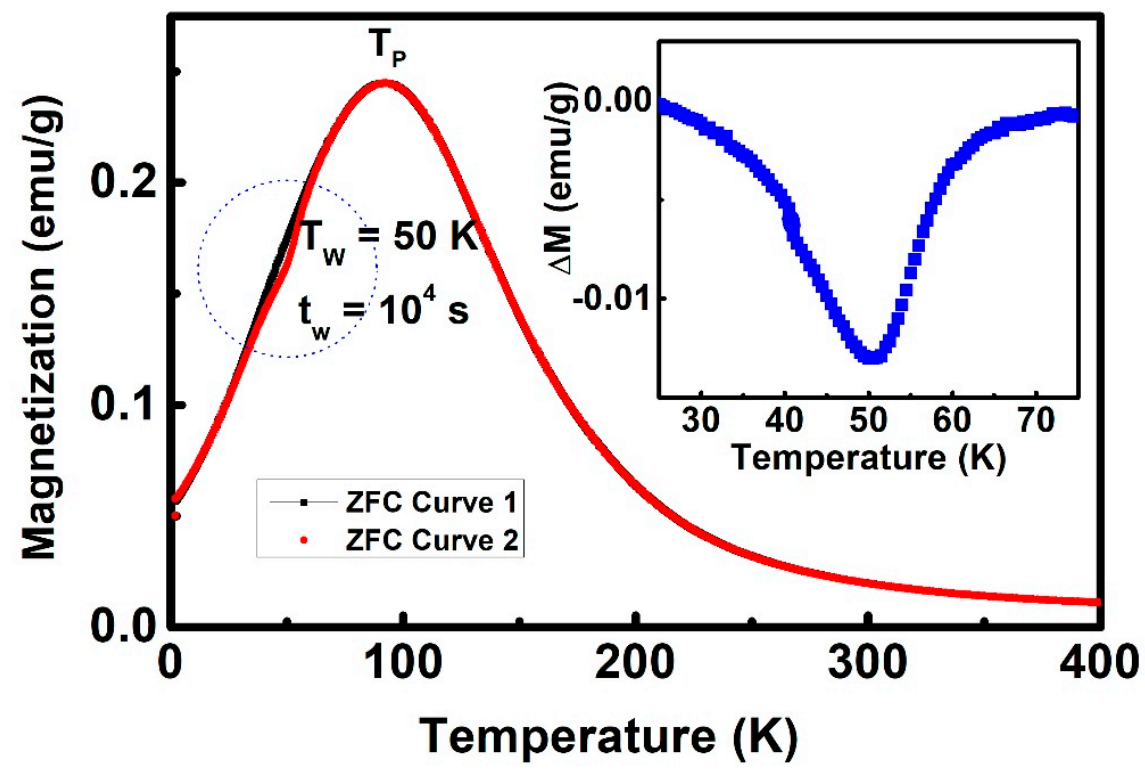

Figure 2. Temperature dependence of ZFC magnetization with (red line) and without (black line) the stop-and-wait protocol (at $\mathrm{T}=50 \mathrm{~K}, \mathrm{t}_{\mathrm{W}}=10^{4} \mathrm{~s}$ ) measured under an external 200 Oe field. The inset shows the difference between Curve 1 and Curve 2 around $\mathrm{T}=50 \mathrm{~K}$.

Figure 3a,b show the magnetic hysteresis $(\mathrm{M}-\mathrm{H})$ loops measured for the prepared $\mathrm{Ni}_{50} \mathrm{Mn}_{36} \mathrm{Ga}_{14}$ alloy after the ZFC and FC. The M-H loops were recorded at different temperatures and magnetic fields applied in the range from $-0.5 \mathrm{kOe}$ to $+0.5 \mathrm{kOe}$ after the $\mathrm{ZFC}$ and FC from $400 \mathrm{~K}$. As shown in Figure 3a, VMS is not observed at ZFC. This is because at ZFC, the FM clusters are randomly orientated. For the $\mathrm{Ni}_{50} \mathrm{Mn}_{36} \mathrm{Ga}_{14}$ alloy, the $\mathrm{M}-\mathrm{H}$ loops show an $\mathrm{M}_{\mathrm{E}}=6.34 \mathrm{emu} / \mathrm{g}$ along with the same direction as the cooling field (shown in Figure $3 b$ ), i.e., positive cooling field $\left(\mathrm{H}_{\mathrm{CF}}\right)$ results in an upward $\mathrm{M}_{\mathrm{E}}$. This is a typical signature of the system over energy barriers and stabilizes a spin-reconfigured state so that a 
magnetization-shifted hysteresis loop occurs in the field-cooled state [5]. Further, it is symmetrically opposite with respect to the $\mathrm{M}-\mathrm{H}$ performed under $\mathrm{H}_{\mathrm{CF}}=-20 \mathrm{kOe}$, indicating that the observed VMS did not originate from the non-saturated minor loop.

(a)
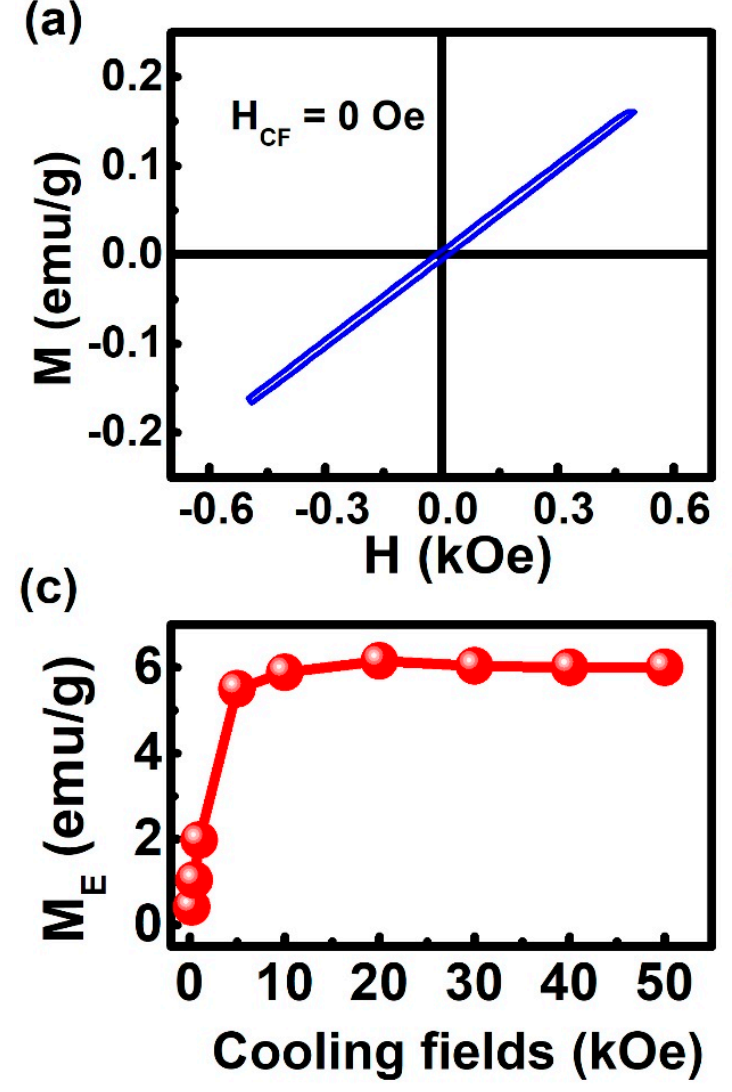

(b)
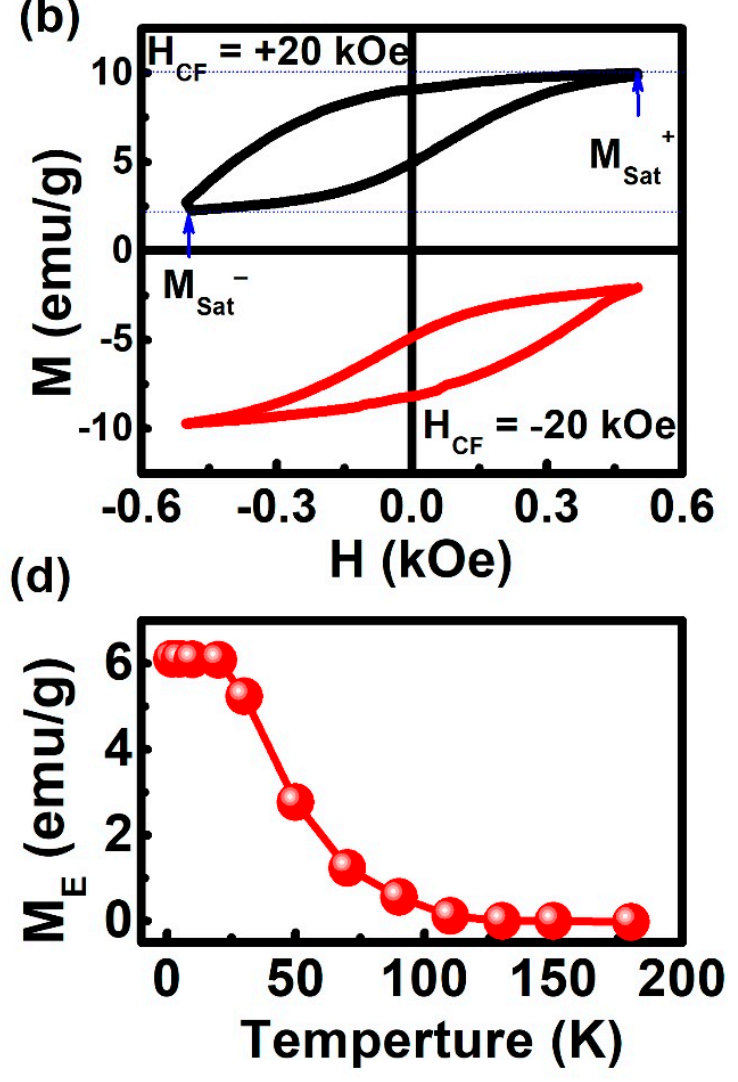

Figure 3. (a,b) Magnetic hysteresis $(\mathrm{M}-\mathrm{H})$ loops obtained for the $\mathrm{Ni}_{50} \mathrm{Mn}_{36} \mathrm{Ga}_{14}$ alloy at different cooling fields ( $0 \mathrm{Oe}, \pm 20 \mathrm{kOe}$ ). (c) $\mathrm{M}_{\mathrm{E}}$ as a function of $\mathrm{Hmax}_{\operatorname{man}} \mathrm{Ni}_{50} \mathrm{Mn}_{36} \mathrm{Ga}_{14}$ at $2 \mathrm{~K}$ after different $\mathrm{H}_{\mathrm{CF}}$. (d) $\mathrm{M}_{\mathrm{E}}$ as a function of temperature in $\mathrm{Ni}_{50} \mathrm{Mn}_{36} \mathrm{Ga}_{14}$ after $20 \mathrm{kOe}$.

As shown in Figure 3c, the calculated variation of $\mathrm{M}_{\mathrm{E}}$ initially increased monotonically with increasing cooling field and stabilized after $20 \mathrm{kOe}$. The $\mathrm{M}_{\mathrm{E}}$ value increased with an increasing cooling field. This is because the degree of alignment of FM clusters enhanced with the cooling field, leading to a unidirectional exchange anisotropy. The spins at the interface exert a microscopic torque, and AFM clusters may restrict themselves to the FM clusters. When the cooling field reached $20 \mathrm{kOe}$, the unidirectional FM anisotropy reached its maximum, and the maximum VMS was observed (Figure 3c).

The dependence of $\mathrm{M}_{\mathrm{E}}$ on the temperature and cooling field was also investigated in this study. Figure $3 \mathrm{~d}$ shows the temperature dependence of $\mathrm{M}_{\mathrm{E}}$ for the $\mathrm{Ni}_{50} \mathrm{Mn}_{36} \mathrm{Ga}_{14}$ alloy under $\mathrm{H}_{\mathrm{CF}}=20 \mathrm{kOe}$ from $400 \mathrm{~K} . \mathrm{M}_{\mathrm{E}}$ decreased with increasing temperature and reached zero at $100 \mathrm{~K}$. This can be explained by the reduction in unidirectional FM anisotropy with increasing temperature.

The magnitude of the measurement field has a significant influence on the interaction between FM and AFM. Figure 4 shows the hysteresis loop of the sample at different measuring fields and the trend of $\mathrm{M}_{\mathrm{E}}$ changing with the measuring field at $2 \mathrm{~K}$ under $=20 \mathrm{kOe}$. As shown in Figure $4 \mathrm{a}-\mathrm{d}$, even if the measuring field is increased to $30 \mathrm{kOe}$, the VMS phenomenon still exists, although the VMS behavior becomes weaker at the large measuring field. Figure $4 \mathrm{e}$ plots the variation of $\mathrm{M}_{\mathrm{E}}$ with the magnitude of the measuring field, and it can be illustrated that the $\mathrm{M}_{\mathrm{E}}$ decreases monotonously with the increase of the measurement field. At the same time, it is worth noting that the VMS behavior is always accompanied by a conventional EB effect, which has been reported in other systems [13-18,36]. This is because the physical origin of the two phenomena in the same system is the same [36]. 

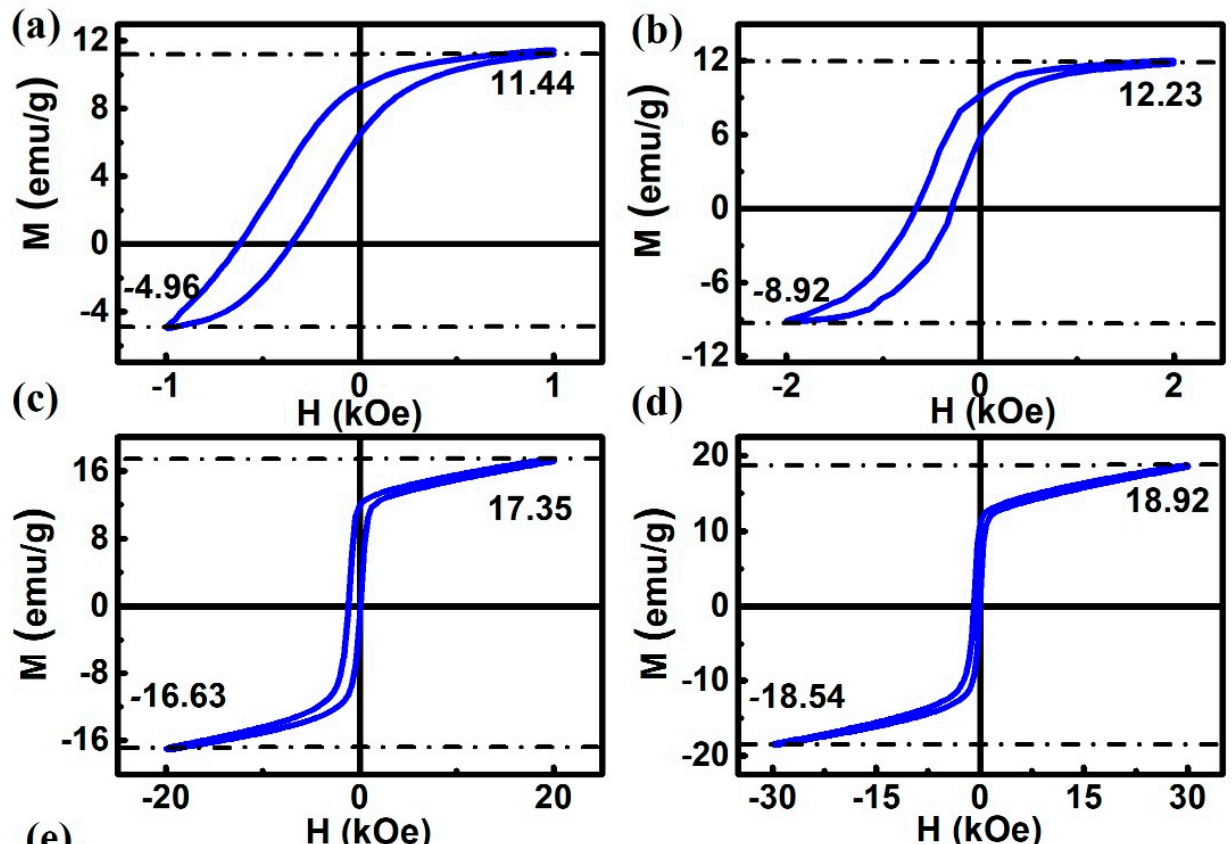

(d)
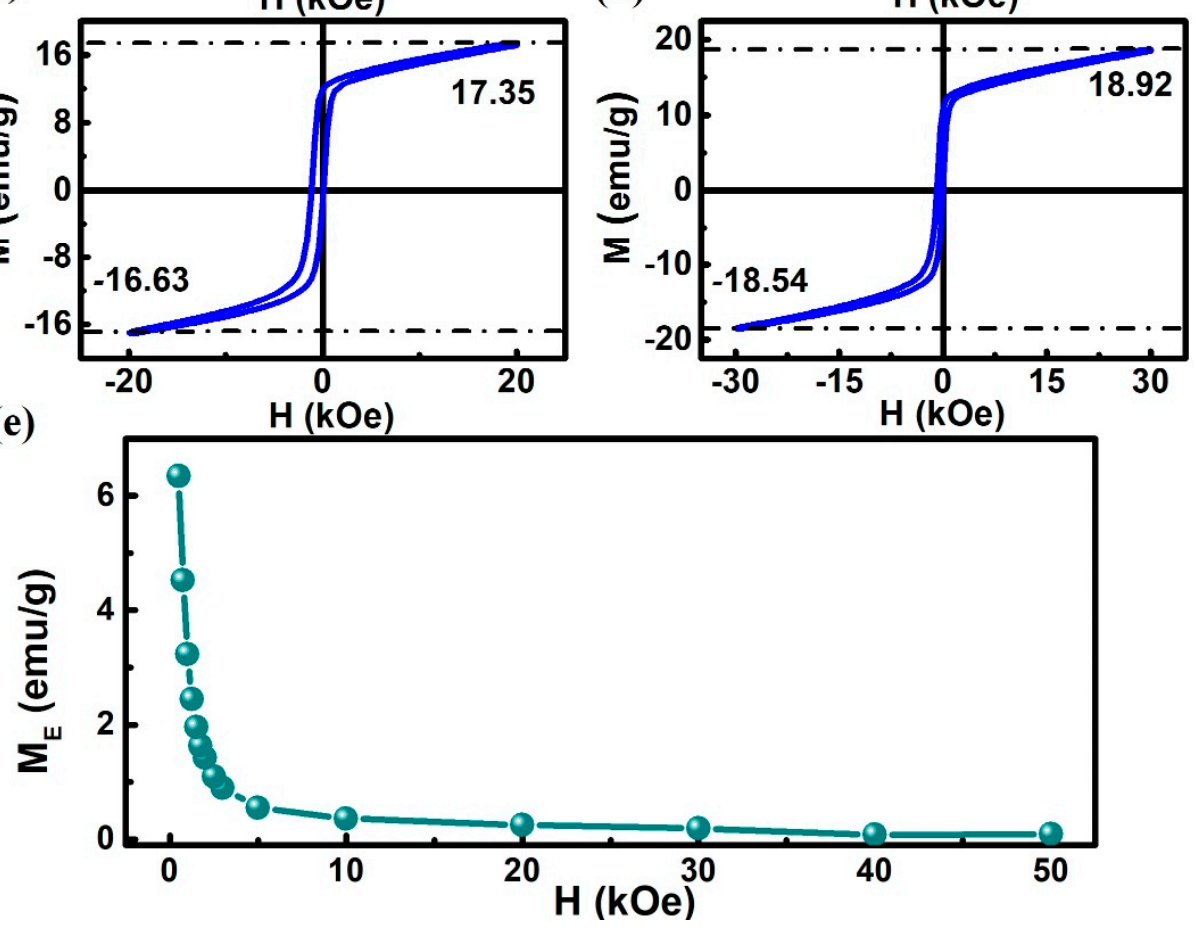

Figure 4. (a-d) $\mathrm{M}-\mathrm{H}$ loops obtained for the $\mathrm{Ni}_{50} \mathrm{Mn}_{36} \mathrm{Ga}_{14}$ alloy at different measuring fields at $\mathrm{H}_{\mathrm{CF}}=20 \mathrm{kOe}$. (e) $\mathrm{M}_{\mathrm{E}}$ as a function of measuring fields in $\mathrm{Ni}_{50} \mathrm{Mn}_{36} \mathrm{Ga}_{14}$ under a cooling field of $20 \mathrm{kOe}$.

The training effect is an inherent characteristic of the exchange bias effect (including EB and VMS), and the magnetic state of the material can be studied through the training effect. Figure 5 shows the hysteresis loops measured from the first to 15th of the sample after FC down to $2 \mathrm{~K}$ under $20 \mathrm{kOe}$. As shown in Figure 5, after the first few cycles, the value of $\mathrm{M}_{\mathrm{E}}$ gradually decreases with the number of cycles (n). The first loop exhibits an $\mathrm{M}_{\mathrm{E}}$ of $\sim 6.34 \mathrm{emu} / \mathrm{g}$. This value decreases to $5.82 \mathrm{emu} / \mathrm{g}$ when $n=$ 11. At $\mathrm{n}>11, \mathrm{M}_{\mathrm{E}}$ almost keeps constant. Such a tendency of $\mathrm{M}_{\mathrm{E}}$ to change with $n$ is similar to other literature $[37,38] . \mathrm{M}_{\mathrm{E}}$ first decreases with $n$ and then becomes stable with a further increase of $\mathrm{n}$ being mainly due to the reconfiguration of some spins during the initial cycles and their stabilization in the subsequent cycles. 
(a)

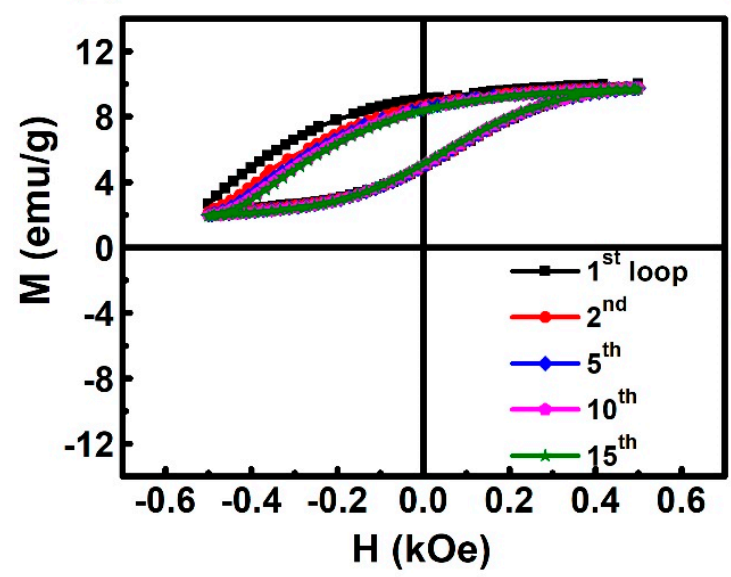

(b)

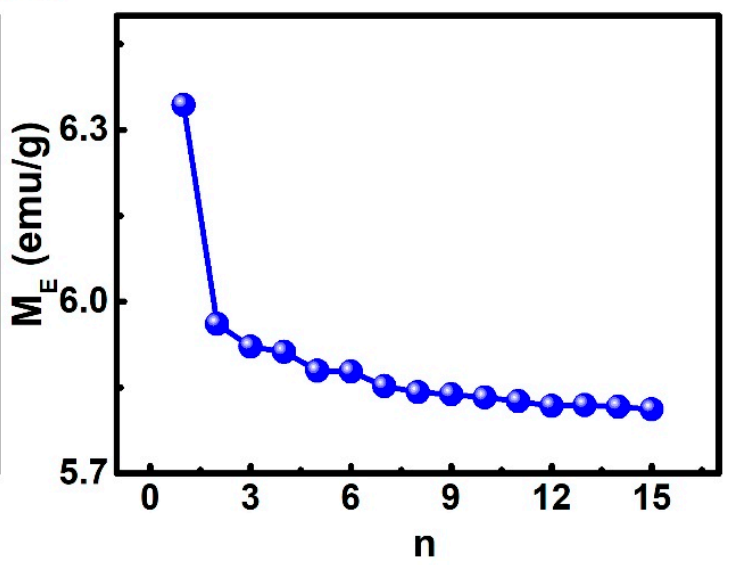

Figure 5. (a) Training effect of the $\mathrm{Ni}_{50} \mathrm{Mn}_{36} \mathrm{Ga}_{14}$ alloy. hysteresis loops measured at temperature $\mathrm{T}$ $=2 \mathrm{~K}$ after field cooling (FC) under $20 \mathrm{kOe}$ from 400 down to $2 \mathrm{~K}$. (b) $\mathrm{M}_{\mathrm{E}}$ as a function of field cycle number $n$.

To further investigate the origin of the spin reconfiguration in the glassy magnetic state, the temperature dependence of the real part $\left(\chi^{\prime}\right)$ of AC susceptibility was recorded at different frequencies $(13,33,53,133,333$, and $633 \mathrm{~Hz})$ after different cooling fields, and the resulting curves are shown in Figure 6. It is illustrated in Figure 5 that at all cooling fields, the $\chi^{\prime}$ peak shifts towards higher temperatures, and its value decreases as the frequency increases.
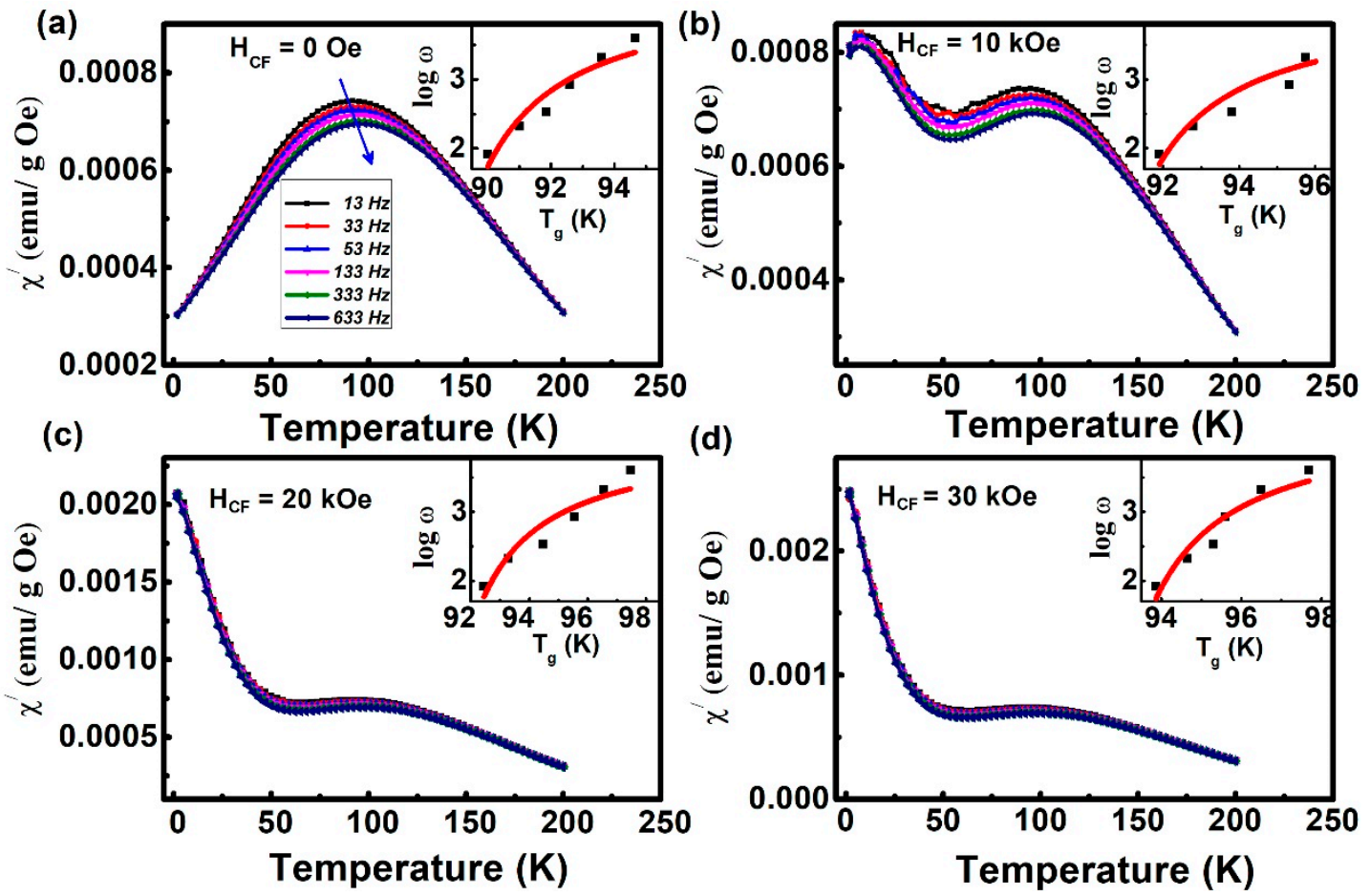

(d)

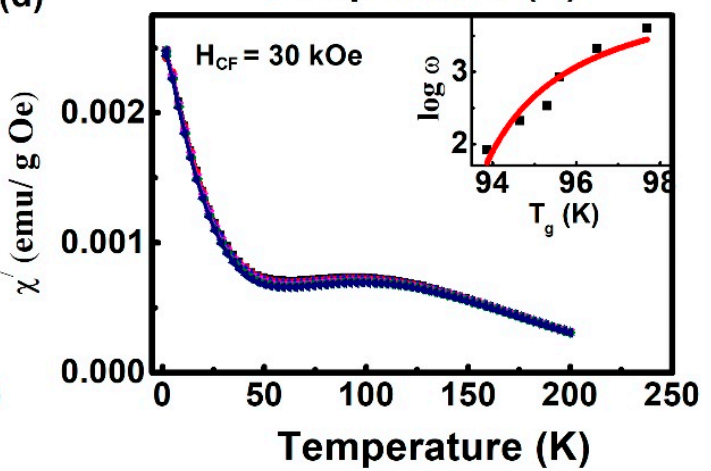

Figure 6. The temperature dependence of the real part of AC susceptibility is measured at different frequencies with an AC magnetic field of 2 Oe under different cooling field 0 Oe (a), $10 \mathrm{kOe}(\mathbf{b}), 20$ $\mathrm{kOe}(\mathbf{c}), 30 \mathrm{kOe}(\mathrm{d})$. The inset shows the correlation between angular frequency and temperature $\left(T_{f}\right)$. The frequency $(\omega)$ dispersion behavior of temperature $\left(T_{g}\right)$ conforms to the Vogel-Fulcher $(V-F)$ relationship. The arrows indicate the direction of increasing frequencies. 
The Vogel-Fulcher (V-F) relationship could be employed to analyze the SG-like behavior $[39,40]$ of the sample,

$$
\omega=\omega_{0} \exp \left[-\mathrm{E}_{\mathrm{a}} / \mathrm{k}_{\mathrm{B}}\left(\mathrm{T}_{\mathrm{f}}-\mathrm{T}_{0}\right)\right]
$$

where $\omega$ is the measured angular frequency; $\omega_{0}$ is the characteristic frequency of SG; Ea is the activation energy of SG; $k_{B}$ is the Boltzmann constant; $T_{f}$ is the peak temperature on the $\chi^{\prime}-T$ curves; $\mathrm{T}_{0}$ is the V-F temperature that describes the interaction among SG clusters. $\tau_{0}=2 \pi / \omega_{0}$ is the microscopic relaxation time related to the nanoclusters in SG. From the previous literature, $\tau_{0}$ varies from $10^{-5}-10^{-12}$ for SG [24,41]. Through fitting, Ea, $\mathrm{T}_{0}$, and $\tau_{0}$ were all obtained, as given in Table 1 . It is obvious from Table 1 that all the characteristic parameters fall in the typical value ranges of SG. As the cooling field increases, $\tau_{0}$ becomes larger. Note that the size of the nanoclusters in SG is smaller, and $\tau_{0}$ would be smaller. Thus, the size of the FM cluster in SG increases as the cooling field increases, which suggests spin reconfiguration with the cooling field increasing indeed occurs [5]. Combining the results given in Figure 3, it can be speculated that the spin reconfiguration of FM clusters with the cooling field plays an essential role in the VMS behavior of the sample.

Table 1. Values of the parameters obtained by fitting the experimental data to Equation (1).

\begin{tabular}{cccc}
\hline Cooling Field (kOe) & $\mathbf{T}_{\mathbf{0}}(\mathbf{K})$ & $\boldsymbol{\tau}_{\mathbf{0}}(\mathbf{s})$ & $\mathbf{E}_{\mathbf{a}} / \mathbf{K}_{\mathbf{B}}(\mathbf{K})$ \\
\hline 0 & 87.1 & $5.1 \times 10^{-9}$ & 621.5 \\
10 & 89.3 & $9.7 \times 10^{-7}$ & 648.2 \\
20 & 90.1 & $8.4 \times 10^{-6}$ & 669.1 \\
30 & 91.7 & $3.5 \times 10^{-5}$ & 752.8 \\
\hline
\end{tabular}

\section{Discussion}

Figure 7 thus schematically illustrates the proposed evolution process of the magnetic structure of the sample giving rise to the VMS phenomenon. As the sample is cooled from $400 \mathrm{~K}$ to $2 \mathrm{~K}$ under a cooling field, the initially randomly oriented FM spins (Figure 7(b1)) are reconfigured to the direction of the cooling field, and the size of FM domains increases with the increase of the cooling field. Removing the cooling field, most of the FM domains would keep the field direction, and some of them deviate from the field direction by a small angle (Figure $7 \mathrm{~b}(2)$ and (3)) [5]

Starting from the FM spin state given by high field cooling (Figure $7 \mathrm{~b}(3)$ ), when applying a magnetic field (the same as the cooling field direction), all the FM spins would orient along the field direction (Figure $7 \mathrm{~b}(4)$ ). As the field reduces to zero, some of the FM spins would deviate from a positive direction. When further applying the opposite magnetic field, the FM spins would try to orient towards the negative direction. Still, due to the interaction among the AFM matrix and the FM spins, the FM spins would deviate from the positive direction only by a small angle (Figure $7 \mathrm{~b}(5)$ ) and Figure $7 \mathrm{~b}(6))$. Thus, the average magnetization of the sample still keeps a positive value. When reducing the negative field to zero, the FM spins would deviate from the positive direction by a smaller angle, and thus, the average magnetization of the sample becomes a larger positive value as compared to that at the maximum opposite field (Figure $7 \mathrm{~b}(7)$ ). In other words, the materials behave as if an extra (internal) biasing field exists, which leads to the hysteresis loop shifting in the magnetization axis [13-16].

Note that a minor loop might induce a similar magnetization shift [42]. However, the M-H loops measured at high magnetic fields such as $30 \mathrm{kOe}$ still show a similar VMS behavior, although the $\mathrm{M}_{\mathrm{E}}$ value is smaller. Therefore, the possibility that the above VMS phenomenon is caused by the small external magnetic field (500 Oe) used here could be excluded. 


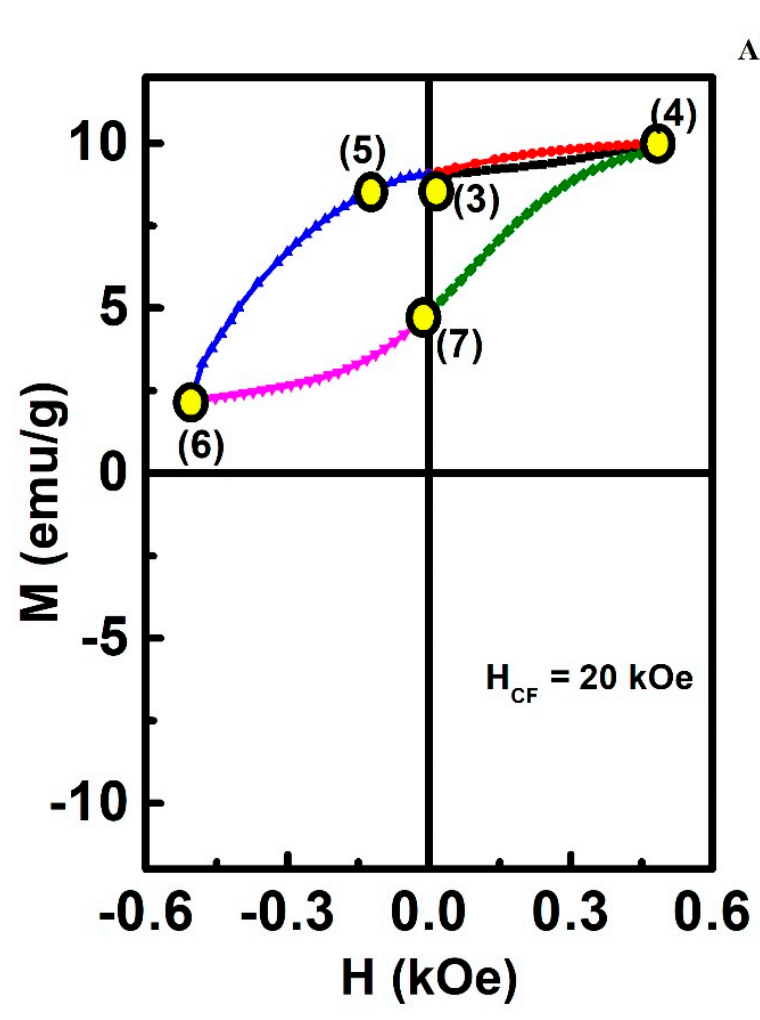

(a)

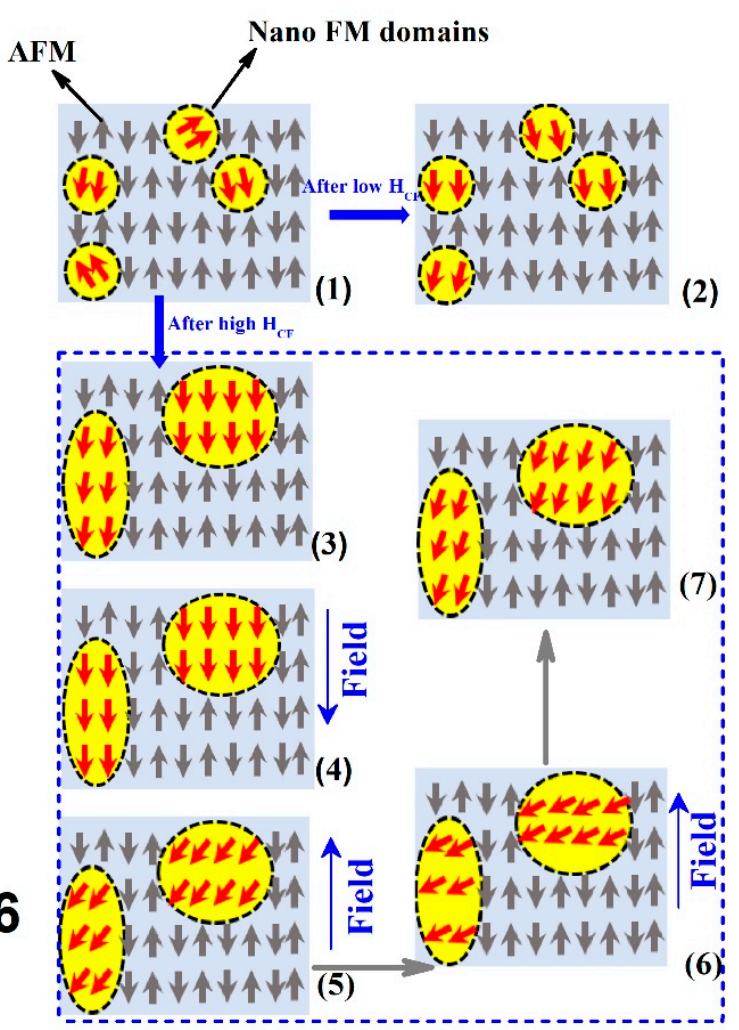

(b)

Figure 7. (a) Hysteresis loops after $\mathrm{H}_{\mathrm{CF}}=20 \mathrm{kOe}$ at $2 \mathrm{~K}$. (b) Schematic illustration of the effect of the cooling field on the relative proportions of the FM and AFM, where FM and AFM represent the ferromagnetic domain and antiferromagnetic matrix, respectively.

\section{Conclusions}

In summary, for the bulk $\mathrm{Ni}_{50} \mathrm{Mn}_{36} \mathrm{Ga}_{14}$ alloy, a giant $\mathrm{M}_{\mathrm{E}}$ of $6.34 \mathrm{emu} / \mathrm{g}$ was observed when the sample was cooled down from $400 \mathrm{~K}$ under $\mathrm{H}_{\mathrm{CF}}=20 \mathrm{kOe}$. Moreover, $\mathrm{M}_{\mathrm{E}}$ depended on the magnitude of the cooling field. This is mainly due to the difference in the FM cluster size formed by the reconfiguration of FM spins. At the same time, $M_{E}$ decreased with increasing temperature, which could be attributed to the change in FM anisotropy with increasing temperature. This result opens a new direction to achieve the VMS, indicating a way to fabricate VMS samples.

Supplementary Materials: The following are available online at http://www.mdpi.com/1996-1944/13/21/4701/s1: Figure S1: Fifteen cyclic DSC responses of the Ni50Mn36Ga14 alloy, Figure S2: (a) The scanning electron microscopy image of the Ni50Mn36Ga14 alloy. (b) EDS analysis of the element ratio of the annealed alloy, Figure S3: (a) Martensitic transformation behavior of the alloy as-cast and annealed measured by DSC using a cooling/heating rate of $10 \mathrm{~K} / \mathrm{min}$. (b) XRD pattern of alloys at room temperature. (c) Temperature dependence of the magnetization curves for alloys in the as-cast and annealed at the applied magnetic field of 500 Oe for ZFC and FC, respectively, Figure S4: Temperature dependence of resistivity at zero field of the alloy.

Author Contributions: Conceptualization, F.T. and S.Y.; experimental work, data acquisition, and analysis, F.T., Y.Z., C.Z., Q.Z., Z.Y., A.M., and W.Z.; writing, original draft preparation, F.T.; writing, review and editing, F.T., Y.Z., C.Z., S.Y., and X.S.; project administration, X.S. All authors have read and agreed to the published version of the manuscript.

Funding: This work was funded by the National Natural Science Foundation of China (Grant Numbers 51801145, 91963111, and 51802249) and the China Postdoctoral Science Foundation (2018M643630).

Conflicts of Interest: The authors declare no conflict of interest. 


\section{References}

1. Meiklejohn, W.H.; Bean, C.P. New Magnetic Anisotropy. Phys. Rev. 1956, 102, 3866-3876. [CrossRef]

2. Elphck, K.; Vallejo-Fernandez, G.; Klemmer, T.J.; Thiele, J.U.; O'Grady, K. HAMR media based on exchange bias. Appl. Phys. Lett. 2016, 109, 052402. [CrossRef]

3. Albisetti, E.; Scaramuzzi, G.; Rinaldi, C.; Cantoni, M.; Bertacco, R.; Petti, D. Temperature Dependence of the Magnetic Properties of IrMn/CoFeB/Ru/CoFeB Exchange Biased Synthetic Antiferromagnets. Materials 2020, 13, 387. [CrossRef] [PubMed]

4. Mao, H.J.; Song, C.; Cui, B.; Wang, G.Y.; Xiao, L.R.; Pan, F. Room temperature spontaneous exchange bias in (La,Sr) $\mathrm{MnO}_{3} / \mathrm{PbZr}_{0.8} \mathrm{Ti}_{0.2} \mathrm{O}_{3} /(\mathrm{La}, \mathrm{Sr}) \mathrm{MnO}_{3}$ sandwich structure. J. Appl. Phys. 2013, 114, 167. [CrossRef]

5. Çakır, A.C.; Acet, M.; Farle, M. Exchange bias caused by field-induced spin reconfiguration in Ni-Mn-Sn. Phys. Rev. B 2016, 93, 094411. [CrossRef]

6. Kim, G.; Khaydukov, Y.; Bluschke, M.; Suyolcu, Y.E.; Christiani, G.; Son, K.; Dietl, C.; Keller, T.; Weschke, E.; Van Aken, P.A.; et al. Tunable perpendicular exchange bias in oxide heterostructures. Phys. Rev. Mater. 2019, 3, 084420. [CrossRef]

7. Ding, S.; Xue, M.; Liang, Z.; Liu, Z.; Li, R.; Cao, S.; Sun, Y.; Zhao, J.; Yang, W.; Yang, J. Spin switching temperature modulated by the magnetic field and spontaneous exchange bias effect in single crystal $\mathrm{SmFeO}_{3}$. J. Phys. Condens. Matter 2019, 31, 435801. [CrossRef] [PubMed]

8. Coutrim, L.T.; Rigitano, D.; Macchiutti, C.; Mori, T.J.A.; Lora-Serrano, R.; Granado, E.; Sadrollahi, E.; Litterst, F.J.; Fontes, M.B.; Baggio-Saitovitch, E.; et al. Zero-field-cooled exchange bias effect in phase-segregated $\mathrm{La}_{2-x} A_{x} \mathrm{CoMnO}_{6-\delta}(A=\mathrm{Ba}, \mathrm{Ca}, \mathrm{Sr} ; x=0,0.5)$. Phys. Rev. B 2019, 100, 054428. [CrossRef]

9. Liu, J.; Singh, A.; Liu, Y.Y.F.; Ionescu, A.; Kuerbanjiang, B.; Barnes, C.H.W.; Hesjedal, T. Exchange Bias in Magnetic Topological Insulator Superlattices. Nano Lett. 2020, 20, 5315-5322. [CrossRef]

10. Wang, X.X.; Gao, S.; Yan, X.; Li, Q.; Zhang, J.C.; Long, Y.Z.; Ruan, K.Q.; Li, X.G. Giant spontaneous exchange bias obtained by tuning magnetic compensation in samarium ferrite single crystal. Phys. Chem. Chem. Phys. 2018, 20, 3687-3693. [CrossRef]

11. Gumieniczek-Chłopek, E.; Odrobińska, J.; Strączek, T.; Radziszewska, A.; Zapotoczny, S.; Kapusta, C. Hydrophobically Coated Superparamagnetic Iron Oxides Nanoparticles Incorporated into Polymer-Based Nanocapsules Dispersed in Water. Materials 2020, 13, 1219. [CrossRef] [PubMed]

12. Tian, F.; Cao, K.; Zhang, Y.; Zeng, Y.; Zhang, R.; Chang, T.; Zhou, C.; Xu, M.; Song, X.; Yang, S. Giant spontaneous exchange bias triggered by crossover of superspin glass in Sb-doped $\mathrm{Ni}_{50} \mathrm{Mn}_{38} \mathrm{Ga}_{12}$ Heusler alloys. Sci. Rep. 2016, 6, 30801. [CrossRef] [PubMed]

13. Tian, Z.M.; Yuan, S.L.; Yin, S.Y.; Liu, L.; He, J.H.; Duan, H.N.; Li, P.; Wang, C.H. Exchange bias effect in a granular system of $\mathrm{NiFe}_{2} \mathrm{O}_{4}$ nanoparticles embedded in an antiferromagnetic $\mathrm{NiO}$ matrix. Appl. Phys. Lett. 2008, 93, 222505. [CrossRef]

14. Singamaneni, S.R.; Fan, W.; Prater, J.T. Complete vertical MH loop shift in $\mathrm{La}_{0 .}{ }_{7} \mathrm{Sr}_{0 .}{ }_{3} \mathrm{MnO}_{3} / \mathrm{SrRuO}_{3}$ thin film heterostructures. J. Appl. Phys. 2015, 117, 17B711. [CrossRef]

15. Zheng, M.; Li, X.; Xiao, W.; Wang, W.; Ni, H. Oxygen deficiency and cooling field driven vertical hysteretic shift in epitaxial $\mathrm{SrRuO}_{3} / \mathrm{SrTiO}_{3}$ heterostructures. Appl. Phys. Lett. 2017, 111, 152405. [CrossRef]

16. Zhou, G.; Ji, H.; Lin, W.; Zhang, J.; Bai, Y.; Chen, J.; Wu, M.; Xu, X. Orbital reconstruction mediated giant vertical magnetization shift and insulator-to-metal transition in superlattices based on antiferromagnetic manganites. Phys. Rev. B. 2020, 101, 024422. [CrossRef]

17. Tho, P.T.; Kim, D.H.; Phan, T.L.; Dang, N.V.; Lee, B.W. Intrinsic exchange bias and vertical hysteresis shift in $\mathrm{Bi}_{0.84} \mathrm{La}_{0.16} \mathrm{Fe}_{0.96} \mathrm{Ti}_{0.04} \mathrm{O}_{3}$. J. Magn. Magn. Mater. 2018, 462, 172-177. [CrossRef]

18. Zheng, M.; Wang, W. Tunable Ferromagnetic Transition Temperature and Vertical Hysteretic Shift in $\mathrm{SrRuO}_{3}$ Films Integrated on Si(001). ACS Appl. Mater. Interfaces 2016, 8, 14012-14018. [CrossRef]

19. Krenke, T.; Duman, E.; Acet, M.; Wassermann, E.F.; Moya, X.; Manosa, L.; Planes, A. Inverse magnetocaloric effect in ferromagnetic Ni-Mn-Sn alloys. Nat. Mater. 2005, 4, 450-454. [CrossRef]

20. Sutou, Y.; Imano, Y.; Koeda, N.; Omori, T.; Kainuma, R.; Ishida, K.; Oikawa, K. Magnetic and martensitic transformations of $\operatorname{NiMnX}(\mathrm{X}=\mathrm{In}, \mathrm{Sn}, \mathrm{Sb})$ ferromagnetic shape memory alloys. Appl. Phys. Lett. 2004, 85, 4358. [CrossRef] 
21. Lünser, K.; Diestel, A.; Nielsch, K.; Fähler, S. Influencing Martensitic Transition in Epitaxial Ni-Mn-Ga-Co Films with Large Angle Grain Boundaries. Materials 2020, 13, 3674. [CrossRef] [PubMed]

22. Krenke, T.; Acet, M.; Wassermann, E.F.; Moya, X.; Mañosa, L.; Planes, A. Martensitic transitions and the nature of ferromagnetism in the austenitic and martensitic states of Ni-Mn-Sn alloys. Phys. Rev. B 2005, 72, 014412. [CrossRef]

23. Tian, F.; Zeng, Y.; Xu, M.; Yang, S.; Lu, T.; Wang, J.; Chang, T.; Adil, M.; Zhang, Y.; Zhou, C.; et al. A magnetocaloric effect arising from a ferromagnetic transition in the martensitic state in Heusler alloy of $\mathrm{Ni}_{50} \mathrm{Mn}_{36} \mathrm{Sb}_{8} \mathrm{Ga}_{6}$. Appl. Phys. Lett. 2015, 107, 012406. [CrossRef]

24. Raji, G.R.; Uthaman, B.; Rajan, R.K.; Sharannia, M.P.; Thomas, S.; Suresh, K.G.; Varma, M.R. Martensitic transition, spin glass behavior and enhanced exchange bias in Si substituted $\mathrm{Ni}_{50} \mathrm{Mn}_{36} \mathrm{Sn}_{14}$ Heusler alloys. RSC Adv. 2016, 6, 32037-32045. [CrossRef]

25. Barandiarán, J.M.; Chernenko, V.A.; Gutiérrez, J.; Orúe, I.; Lázpita, P. Magnetostriction in the vicinity of structural transitions in $\mathrm{Ni}_{2} \mathrm{MnGa}$. Appl. Phys. Lett. 2012, 100, 262410. [CrossRef]

26. Hinterleitner, B.; Knapp, I.; Poneder, M.; Shi, Y.; Müller, H.; Eguchi, G.; Eisenmenger-Sittner, C.; Stöger-Pollach, M.; Kakefuda, Y.; Kawamoto, N.; et al. Thermoelectric performance of a metastable thin-film Heusler alloy. Nature 2019, 576, 85-90. [CrossRef]

27. Ye, M.; Kimura, A.; Miura, Y.; Shirai, M.; Cui, Y.T.; Shimada, K.; Namatame, H.; Taniguchi, M.; Ueda, S.; Kobayashi, K.; et al. Role of Electronic Structure in the Martensitic Phase Transition of $\mathrm{Ni}_{2} \mathrm{Mn}_{1+\mathrm{x}} \mathrm{Sn}_{1-\mathrm{x}}$ Studied by Hard-X-Ray Photoelectron Spectroscopy and Ab Initio Calculation. Phys. Rev. Lett. 2010, 104, 176401. [CrossRef]

28. Xu, X.; Nagasako, M.; Ito, W.; Umetsu, R.Y.; Kanomata, T.; Kainuma, R. Magnetic properties and phase diagram of $\mathrm{Ni}_{50} \mathrm{Mn}_{50-\mathrm{x}} \mathrm{Ga}_{\mathrm{x}}$ ferromagnetic shape memory alloys. Acta Mater. 2013, 61, 6712-6723. [CrossRef]

29. Han, Z.D.; Qian, B.; Wang, D.H.; Zhang, P.; Jiang, X.F.; Zhang, C.L.; Du, Y.W. Magnetic phase separation and exchange bias in off-stoichiometric Ni-Mn-Ga alloys. Appl. Phys. Lett. 2013, 103, 172403. [CrossRef]

30. Vasil'ev, A.N.; Buchel'nikov, V.D.; Takagi, T.; Khovaǔlo, V.V.; Éstrin, É.I. Shape memory ferromagnets. Phys.-Usp. 2003, 46, 559. [CrossRef]

31. Nayak, A.K.; Shekhar, C.; Winterlik, J.; Gupta, A.; Felser, C. $\mathrm{Mn}_{2}$ PtIn: A tetragonal Heusler compound with exchange bias behavior. Appl. Phys. Lett. 2012, 100, 152404. [CrossRef]

32. Winkelmann, A.; Przybylski, M.; Luo, F.; Shi, Y.; Barthel, J. Perpendicular magnetic anisotropy induced by tetragonal distortion of FeCo alloy films grown on Pd (001). Phys. Rev. Lett. 2006, 96, 257205. [CrossRef] [PubMed]

33. Machavarapu, R.; Jakob, G. Exchange bias effect in the martensitic state of Ni-Co-Mn-Sn film. Appl. Phys. Lett. 2013, 102, 232406. [CrossRef]

34. Sharma, J.; Suresh, K.G. Observation of giant exchange bias in bulk $\mathrm{Mn}_{50} \mathrm{Ni}_{42} \mathrm{Sn}_{8}$ Heusler alloy. Appl. Phys. Lett. 2015, 106, 072405. [CrossRef]

35. Kumar, R.; Sharma, J.; Iyer, K.K.; Sampathkumaran, E.V. Reentrant spin-glass and transport behavior of $\mathrm{Gd}_{4} \mathrm{PtAl}$, a compound with three sites for Gd. J. Magn. Magn. Mater. 2019, 490, 165515. [CrossRef]

36. Zheng, R.K.; Wen, G.H.; Fung, K.K.; Zhang, X.X. Giant exchange bias and the vertical shifts of hysteresis loops in $\gamma-\mathrm{Fe}_{2} \mathrm{O}_{3}$-coated Fe nanoparticles. J. Appl. Phys. 2004, 95, 5244. [CrossRef]

37. Polisetty, S.; Sahoo, S.; Binek, C. Scaling behavior of the exchange-bias training effect. Phys. Rev. B. 2007, 76, 184423. [CrossRef]

38. Proenca, M.P.; Ventura, J.; Sousa, C.T.; Vazquez, M.; Araujo, J.P. Exchange bias, training effect, and bimodal distribution of blocking temperatures in electrodeposited core-shell nanotubes. Phys. Rev. B. 2013, 87, 134404. [CrossRef]

39. Bitla, Y.; Kaul, S.N.; Barquín, L.F. Nonlinear susceptibilities as a probe to unambiguously distinguish between canonical and cluster spin glasses. Phys. Rev. B. 2012, 86, 094405. [CrossRef]

40. Bedanta, S.; Kleemann, W. Topical review superparamagnetism. J. Phys. D-Appl. Phys. 2009, 42, 013001. [CrossRef] 
41. Liao, P.; Jing, C.; Wang, X.L.; Yang, Y.J.; Zheng, D.; Li, Z.; Kang, B.J.; Deng, D.M.; Cao, S.X.; Zhang, J.C.; et al. Strongly enhanced antiferromagnetism and giant spontaneous exchange bias in $\mathrm{Ni}_{50} \mathrm{Mn}_{36} \mathrm{Co}_{4} \mathrm{Sn}_{10}$ Heusler alloy. Appl. Phys. Lett. 2014, 104, 092410. [CrossRef]

42. Windsor, Y.W.; Gerber, A.; Karpovski, M. Dynamics of successive minor hysteresis loops. Phys. Rev. B 2012, 85, 064409. [CrossRef]

Publisher's Note: MDPI stays neutral with regard to jurisdictional claims in published maps and institutional affiliations.

(C) 2020 by the authors. Licensee MDPI, Basel, Switzerland. This article is an open access article distributed under the terms and conditions of the Creative Commons Attribution (CC BY) license (http://creativecommons.org/licenses/by/4.0/). 